\title{
Avaliação Ambiental Estratégica de Planos de Bacias Hidrográficas
}

\section{Strategic Environmental Assessment for Watershed Management Plans}

\author{
Denise Gallo Pizella \\ Bióloga. Doutora em Ciências da Engenharia Ambiental pelo Centro de Recursos Hídricos e Ecologia Aplicada (CRHEA), da Escola de Engenharia da \\ Universidade de São Paulo (USP) - São Carlos (SP), Brasil.

\section{Marcelo Pereira de Souza} \\ Engenheiro Civil. Professor Titular da Faculdade de Filosofia, Ciências e Letras da USP de Ribeirão Preto. Professor credenciado ao \\ Programa de Pós-Graduação em Ciências da Engenharia Ambiental do CRHEA, da Escola de Engenharia da USP - São Carlos (SP), Brasil.
}

\begin{abstract}
Resumo
A Avaliação Ambiental Estratégica (AAE) é um instrumento de avaliação de impactos ambientais de Políticas, Planos e Programas (PPPs). Tendo em vista o planejamento dos recursos hídricos no Brasil, o objetivo deste artigo foi avaliar as contribuições da AAE para a elaboração de Planos de Bacias Hidrográficas no país, tendo como objeto de estudo a Bacia do Rio Pardo, no estado de São Paulo. Para tanto, realizaram-se entrevistas com colaboradores do Comitê e acompanhou-se o Grupo de Trabalho do Relatório de Situação dos Recursos Hídricos. Verificou-se que a aplicação da AAE permitiria a incorporação dos princípios de sustentabilidade ambiental no desenvolvimento dos Planos; a integração com outros PPPs correlatos; o levantamento e avaliação de impactos de alternativas de desenvolvimento na Bacia e a identificação de indicadores para o monitoramento do Plano de forma contínua.
\end{abstract}

Palavras-chave: planos de bacias hidrográficas; avaliação ambiental estratégica; planejamento ambiental.

\begin{abstract}
Strategic Environmental Assessment (SEA) is a tool for assessing environmental impacts of Policy, Plans and Programmes (PPPs). In view of the water resources planning in Brazil, this paper aimed to evaluate the contributions of the SEA for the development of Watershed Management Plans in the country, having as object the Pardo's River Basin, in state of Sao Paulo. To this end, we carried out interviews with staff of the Committee and followed the Working Group of the Status Report of Water Resources. It was found that the application of SEA allowed the incorporation of the environmental sustainability principles in the development of Plans, the integration with other related PPPs, the survey and impact assessment of the development alternatives in the Basin and the identification of indicators for monitoring the Plan.
\end{abstract}

Keywords: watershed management plans; strategic environmental assessment; environmental planning.

\section{Introdução}

A Política Nacional de Recursos Hídricos (PNRH), Lei No. 9433/97 tem como um de seus instrumentos a elaboração de Planos de Recursos Hídricos (PRH), definidos como planos diretores de longo prazo que fundamentam a implementação da Política Nacional de Recursos Hídricos e seu gerenciamento. Sua elaboração pode ser por bacia hidrográfica, estado ou país. Dentre os Planos de RH, situam-se os Planos de Bacias Hidrográficas a serem elaborados pelos Comitês de Bacia Hidrográfica, compostos por representantes da União, dos estados e Distrito Federal, municípios, usuários das águas e entidades civis situados na bacia hidrográfica em questão (BRASIL, 1997).
Para que a realização de um Plano de Bacia Hidrográfica promova a inserção das variáveis ambientais durante todas as fases de sua elaboração, são necessárias a identificação dos fatores ambientais existentes e das suscetibilidades e vocações ambientais para a implementação dos programas derivados; o levantamento de alternativas para suas metas, considerando os potenciais impactos ambientais de longo prazo, indiretos e cumulativos e o cumprimento e compatibilização das Políticas, Planos e Programas federais, regionais e municipais existentes. Nesse sentido, há uma crescente aplicação do instrumento de política ambiental conhecido por Avaliação Ambiental Estratégica (AAE), que tem por objetivo a avaliação ambiental de Políticas, Planos e Programas (PPPs), na elaboração de Planos de Bacias Hidrográficas (GULLÓN, 2005). Apesar das variações metodológicas 
do instrumento de acordo com a Política, Plano e Programa a serem avaliados e do contexto de cada país, a AAE tem como princípios básicos (THERIVEL, 2004):

- Inserção das questões ambientais nas tomadas de decisões estratégicas;

- Possibilidade de avaliação de ações estratégicas em recortes territoriais amplos e não pontuais;

- Participação social nas etapas do planejamento;

- Aprimoramento e compatibilização de Políticas, Planos e Programas;

- Auxílio na criação de Termos de Referência para os Estudos de Impacto Ambiental;

- Consideração das alternativas de localização e tecnológicas, considerando as vocações e suscetibilidades do meio-ambiente;

- Avaliação dos potencias impactos ambientais indiretos e cumulativos das ações estratégicas;

- Promoção da integração institucional, pois necessita da coordenação de ações das diversas instâncias e setores governamentais;

- Permite uma maior transparência nas tomadas de decisão, em função da participação social. Desse modo, evita que haja a predominância de interesses de grupos com maior articulação política nos processos decisórios;

- É um instrumento com possibilidade de retroalimentação, em função da necessidade de monitoramento das decisões tomadas.

De acordo com Gullón (2005) e Porto \& Tucci (2009), no setor hídrico, a utilização da AAE nas tomadas de decisão é fundamental, pois a qualidade das águas reflete a qualidade do ambiente como um todo. Devido a isso, a Diretiva Europeia sobre a AAE (Directive 2001/42/EC) requer a realização de uma AAE paralelamente à elaboração de PPPs relacionadas à gestão hídrica, dentre os quais se situam os Planos de Bacia Hidrográfica. Em função das avaliações de impacto ambiental serem instrumentos proativos e preventivos, sua aplicação

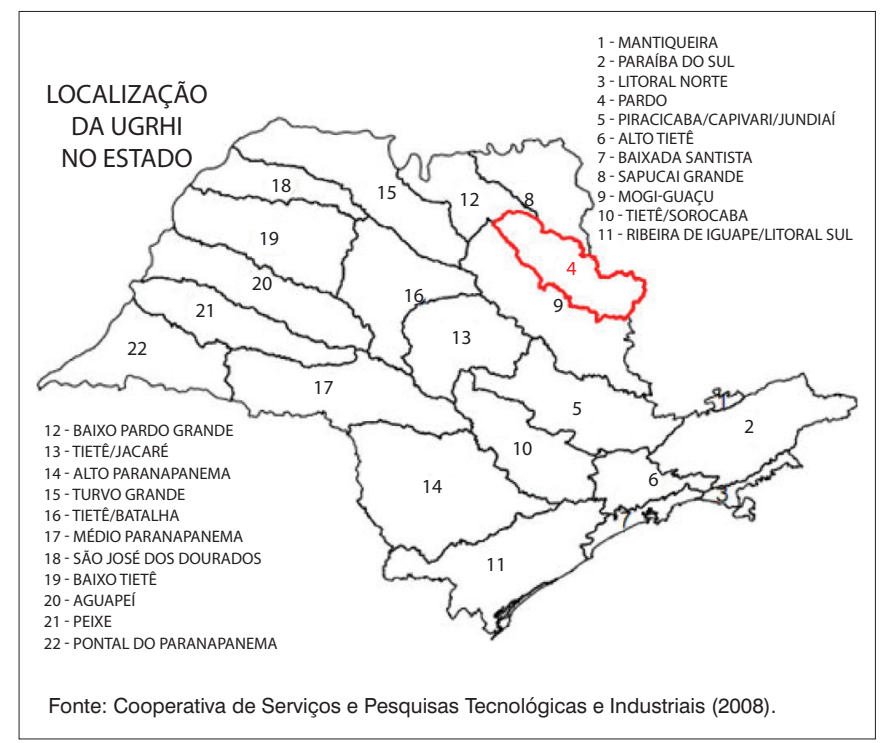

Figura 1 - Localização da Bacia do Rio Pardo no estado de São Paulo (UGRHI 04). é mais eficiente quando nos estágios iniciais da proposição de estratégias, integrando-se nas etapas de planejamento que antecedem os projetos pontuais. Em relação à água, os projetos realizados nesse setor apresentam potenciais efeitos socioambientais indiretos, como, por exemplo, sobre os usos do solo nos meios rural e urbano. Tais consequências necessitam ser previamente identificadas e a AAE possui potencial para auxiliar nesse processo (GULLÓN, 2005).

Tendo em vista esse cenário de planejamento de recursos hídricos, procurou-se avaliar as contribuições da AAE para a elaboração de Planos de Bacias Hidrográficas, tendo como objeto de estudo a Bacia do Rio Pardo, situada no estado de São Paulo.

\section{Área de estudo}

A Bacia Hidrográfica do Rio Pardo, localizada no estado de São Paulo, foi definida como a Unidade de Gerenciamento de Recursos Hídricos 04 (UGRHI 04) pela Lei Nº 9.034/94, que dispõe sobre o Plano Estadual de Recursos Hídricos para o biênio 1994/95. Essa Unidade possui área de 8.991,02 km² e localiza-se na área de abrangência da Diretoria Regional do DAEE da Bacia do Pardo Grande. Seu limite ao norte é a UGRHI 8 (Sapucaí/Grande), a nordeste a UGRHI 12 (Baixo Pardo/Grande), a sudoeste a UGRHI 9 (Rio Mogi-Guaçu) e a Leste-Sudoeste o estado de Minas Gerais, conforme apresentado na Figura 1.

\section{Metodologia}

A metodologia foi desenvolvida nas seguintes etapas:

1. Análise crítica do Plano de Bacia Hidrográfica do Rio Pardo, de modo a contemplar: os critérios utilizados para o diagnóstico da situação atual dos recursos hídricos e dos demais fatores ambientais e sociais intervenientes; a existência de análise de outras estratégias de cunho setorial e territorial nos âmbitos federal, estadual e municipal relacionadas com a gestão hídrica da Bacia, de modo a verificar as oportunidades e restrições para a realização das metas propostas no Plano; as metas dos Planos de Bacia, avaliando-as quanto à pertinência frente aos diagnósticos realizados, o grau de detalhamento e clareza para sua implementação, os prazos fixados, meios para concretizá-las e a existência de indicadores de performance; os mecanismos de monitoramento adotados para a verificação do cumprimento das metas, as dificuldades encontradas e a proposição de possíveis modificações nos objetivos e metas do Plano em horizontes de curto, médio e longo prazos.

2. Realização de entrevistas com sete membros do Comitê de Bacia (contemplando os setores de usuários, da sociedade civil organizada e de órgãos ambientais), de modo a obter informações e opiniões sobre o conteúdo do Plano de Bacia, especialmente quanto aos dados utilizados e seu tratamento para compor o diagnóstico, o conteúdo das metas, as dificuldades e oportunidades para seu alcance e o acompanhamento do Plano. Para tanto, elaborou-se um questionário 
semiestruturado contendo as seguintes questões principais, que poderiam ser desenvolvidas de formas variáveis de acordo com as particularidades do entrevistado, cujas identidades permaneceram anônimas:

1. Você fez parte da elaboração do Plano de Bacia ou de sua revisão?

2. Foram realizadas consultas públicas em sua elaboração?

3. Qual sua opinião a respeito das informações que foram utilizadas na elaboração e revisão do Plano em termos de qualidade e disponibilidade?

4. Há articulação entre o Plano de Bacia e os Planos Diretores Municipais?

5. Como você observa a integração entre os órgãos que fazem parte do sistema de gerenciamento dos recursos hídricos?

6. Você acha que a gestão de recursos hídricos se relaciona na prática com outros instrumentos de gestão ambiental? Como isto é feito?

7. Quais os principais conflitos em relação ao uso múltiplo dos recursos hídricos na Bacia?

8. Quais são as perspectivas do Relatório de Situação dos Recursos Hídricos que está sendo elaborado em relação à próxima revisão do Plano de Bacia? E como você vê a construção deste relatório?

9. Quais as dificuldades que você observa no planejamento dos recursos hídricos e o que traria como proposições, em termos de gestão?

3. Observação participante das reuniões realizadas pelo Grupo de Trabalho Permanente do Relatório de Situação dos Recursos Hídricos e do Plano de Bacia, do Comitê de Bacia Hidrográfica do Rio Pardo, responsável pela elaboração dos Relatórios Anuais de Situação dos Recursos Hídricos da UGRHI 4, tendo por objetivo acompanhar as discussões realizadas sobre os indicadores de situação utilizados e propostos pelo Comitê.

A partir das análises realizadas, buscou-se identificar as oportunidades e dificuldades para a utilização da AAE na revisão do Plano de Bacia do Rio Pardo em todas as suas etapas.

\section{Resultados}

Inicialmente, será apresentada a análise do Plano de Bacia do Rio Pardo com alguns comentários dos entrevistados, para em seguida avaliarem-se as potencialidades da Avaliação Ambiental Estratégica em contribuir para elaboração de Planos de Bacia Hidrográficas no país, partindo do modelo de AAE da Diretiva Europeia 2001/42/EC.

\section{Avaliação do Plano de Bacia do Rio Pardo}

\section{Participação na elaboração do Plano de Bacia}

O Plano de Bacia do Rio Pardo foi aprovado em 2002 e revisado em 2008, tendo um horizonte de ação até 2011. Para sua elaboração, foi contratada a Cooperativa de Serviços e Pesquisas Tecnológicas e Industriais (CPTI), com participação do Centro de Tecnologias Ambientais e Energéticas (CETAE) e do Instituto de Pesquisas Tecnológicas (IPT).

A fim de diagnosticar a participação do Comitê no desenvolvimento do Plano, indagou-se aos entrevistados o grau de influência exercido pelo colegiado nesse momento, considerando que o levantamento e tratamento das informações são direcionados pelas demandas levantadas. De modo geral, mencionou-se a pequena influência do Comitê nessa etapa, que pode ser ilustrada nas falas de dois entrevistados:

No início nós tivemos uma dependência dos planos de bacia em função da disponibilização de informações, da necessidade de contratação de empresas específicas para agregar essas informações. [...] eu entendo que o comitê tem que criar suas próprias condições de obter e de disponibilizar essas informações referentes aos planos de bacia.

Foi contratada uma empresa, o IPT na época, uma cooperativa que tinha feito e eles fizeram o contato com as prefeituras [...]. E no meio disso, o IPT que era o responsável, fazia as consultas aos municípios e aos órgãos. Mas eram consultas. Então eu acho que umas duas ou três vezes teve sim alguma reunião mais ampla. Mas eram de esclarecimento. É uma coisa que a gente sente também. A construção foi de consulta, mas não é uma construção de participação.

Tais opiniões são compartilhadas com participantes de outros Comitês do estado de São Paulo, como apresentado no Relatório Avaliação dos 20 anos do Sistema Integrado de Gerenciamento de Recursos Hídricos (EMPINOTTI, 2010). Ao questionar sobre os principais problemas encontrados na elaboração de Planos de Bacia, os participantes destacaram a necessidade de serem elaborados pelo Poder Público em vez de por consultoras, perante discussões internas dos Comitês, a fim de que reflitam suas necessidades.

Objetivos do Plano de Bacia

Quanto aos objetivos do Plano de Bacia do Pardo consta a garantia das gerações atuais e futuras à água em qualidade e disponibilidade adequadas, de modo a garantir a vida e o bem-estar socioeconômico da sociedade, de acordo com o paradigma do desenvolvimento sustentável.

Apesar dos objetivos específicos darem grande ênfase à recuperação ambiental da Bacia, analisando-se o conteúdo e metas do Plano e os indicadores utilizados nos Relatórios de Situação, há a prevalência de uma abordagem setorial da gestão hídrica na Bacia, em que os recursos hídricos são considerados de forma dissociada dos demais aspectos ambientais, tais como a qualidade dos solos, do ar e a biodiversidade existente no território. Essa é a visão que prevalece no diagnóstico do Plano e que reflete a dissociação entre gestão hídrica e ambiental que predomina no país. 


\section{Diagnóstico da Bacia}

No desenvolvimento do diagnóstico do Plano de Bacia, contemplaram-se os seguintes fatores ambientais, sociais e econômicos: tipo de solo; corpos d'água superficiais e subterrâneos; uso e ocupação do solo na bacia (área urbanizada, área rural, vegetação, unidades de conservação existentes, vegetação remanescente e áreas reflorestadas); densidade demográfica; atividades industriais e comércio; principais culturas agrícolas; emprego e renda; biodiversidade e processos erosivos e assoreamento dos corpos d'água.

Quanto à obtenção das informações, utilizaram-se informações essencialmente secundárias, tais como bases cartográficas do Instituto Geográfico (IG) e do Instituto Brasileiro de Geografia e Estatística (IBGE). Quanto às Prefeituras, foram enviados questionários para obtenção de informações relativas à existência e número de erosões nos municípios. Os Planos Diretores Municipais e os Zoneamentos de uso do solo existentes em alguns municípios da Bacia não foram abrangidos no estudo.

Os dados primários, alguns obtidos diretamente com as prefeituras municipais e com as secretarias estaduais e municipais, não foram verificados in loco, o que pode prejudicar o diagnóstico real da bacia, principalmente em se tratando de processos erosivos, situação de remanescentes de vegetação (extensão, localização, estágio sucessional e potenciais agentes impactantes) e biodiversidade (especialmente quanto à situação de espécies indicadoras da qualidade dos ecossistemas, sua população estimada e localização).

O diagnóstico apresentado é basicamente descritivo em alguns aspectos, como em relação ao setor primário da economia e as culturas agrícolas desenvolvidas na bacia, mas carente em outras informações, como aquelas abordadas anteriormente contemplando a biodiversidade, o que o torna ao mesmo tempo incompleto e extenso, fato que pode também dificultar a comunicação com o público interessado.

A inexistência de dados importantes e/ou sua atualização também se mostram como empecilhos a um bom diagnóstico. Nesse ínterim, se destacam a falta de estudos com levantamento topográfico detalhado, investigações geológicas e hidrológicas, além da localização, quantificação dos principais usuários dos recursos hídricos e suas respectivas demandas.

Quanto ao balanço demanda versus utilização da água, aponta-se no Plano de Bacia a necessidade de implantação de outros postos fluviométricos com uma distribuição espacial adequada, a fim de se obter dados hidrológicos mais consistentes para a elaboração de cenários futuros (CPTI, 2008).

O monitoramento da qualidade hídrica é indicado também como outro aspecto a ser aprimorado na Bacia, que conta com quatro pontos de monitoramento para as águas superficiais e 13 para águas subterrâneas, os quais consistem em poços tubulares para abastecimento público, sendo considerados insuficientes frente à área total de contribuição da Bacia.
O diagnóstico não contemplou alguns temas relacionados ao uso e ocupação do solo que exercem grande influência sobre a qualidade e disponibilidade dos recursos hídricos, tais como: transporte, expansão urbana e suas consequências sobre a macrodrenagem e os potenciais impactos derivados de mudanças climáticas. Questões importantes envolvendo a agricultura, uma das atividades mais proeminentes da região, tais como práticas agrícolas adotadas e a influência das queimadas e da expansão da monocultura de cana-de-açúcar sobre os recursos hídricos e os ecossistemas de modo mais abrangente, também não foram abordadas.

Quanto aos Planos setoriais e espaciais que incidem sobre os recursos hídricos, constata-se uma falta de articulação entre políticas setoriais que incidem sobre a gestão dos recursos hídricos. Empinotti (2010) demonstra um consenso entre os gestores de bacias hidrográficas do estado de São Paulo da falta de ligação entre os Planos de Bacia e os Planos Diretores Municipais e setoriais. Isso se dá, de acordo com esses agentes, devido ao desconhecimento dos municípios sobre a existência e relevância desses Planos para a gestão local e também pela visão adotada pelos próprios Comitês de Bacia e do Poder Público em geral de que os Planos servem primordialmente para a tomada de recursos do Fundo Estadual de Recursos Hídricos (FEHIDRO). Além dos municípios, os órgãos setoriais relacionados aos recursos hídricos, como os setores de transporte, agricultura, energia, dentre outros, também não consideram os impactos de suas ações sobre esse recurso natural, fato que dificulta a concretização dos objetivos delineados pelos Planos estaduais de recursos hídricos e de Bacias Hidrográficas.

\section{Cenários e Metas do Plano de Bacia}

O Plano de Bacia apresenta três cenários para a implementação de suas metas no horizonte de planificação de curto prazo, referente aos anos de 2008 a 2001, de médio prazo, entre 2012 e 2015 e de longo prazo, entre 2016 e 2019, quais sejam: cenário desejável, cenário piso e cenário recomendado.

As metas do Plano são muito generalistas, prezando mais pela quantidade de ações a serem desenvolvidas do que pela análise de sua objetividade e factibilidade. Além disso, não há um levantamento a respeito dos investimentos planejados pelos municípios no tocante à gestão dos recursos hídricos, o que pode levar a discrepâncias ou à repetição de medidas, prejudicando o planejamento no âmbito da Bacia hidrográfica. Ademais disso, a falta de indicadores que acompanhem o alcance das metas é outro fator que dificulta a implementação dos Planos.

\section{Monitoramento}

A Política Estadual dos Recursos Hídricos do estado de São Paulo, estabelecida pela Lei $\mathrm{N}^{\circ}$. 7.663/91, determinou como um de seus instrumentos de gestão o Relatório de Situação dos Recursos Hídricos, que tem por objetivo a prestação anual de informações públicas sobre as condições das águas de domínio do estado (GOVERNO DO 
ESTADO DE SÃO PAULO, 2010). Para sua realização, foi proposta, em 2007, uma metodologia envolvendo indicadores para a avaliação dos recursos hídricos estruturados segundo o modelo FPEIR (ForçaMotriz; Pressão; Estado; Impacto; Resposta) utilizado pela European Environment Agency (EEA).

No ano de 2010, a Coordenadoria de Recursos Hídricos efetuou uma redefinição dos indicadores utilizados pela primeira vez em 2009, envolvendo a participação dos Comitês de Bacia do estado. Tal trabalho resultou de um amadurecimento sobre o entendimento dos indicadores do ponto de vista conceitual, metodológico e de representatividade. Desse modo, foram estabelecidos 65 indicadores/parâmetros, sendo 41 básicos, ou seja, que retratam a situação de todas as Bacias estaduais, e 24 específicos para cada Bacia, cuja utilização fica a critério de cada Comitê, pois representam situações próprias de cada Bacia (GOVERNO DO ESTADO DE SÃO PAULO, 2010). No entanto, a não utilização de cada indicador deve se dar de forma justificada, assim como novos indicadores podem ser sugeridos à Coordenadoria de acordo com as necessidades dos Comitês.

O Comitê da Bacia do Rio Pardo efetuou seu primeiro Relatório em 2009, tendo 2008 por ano base e, o segundo, em 2010, com 2009 como ano base. Ambos os Relatórios apresentam uma análise sucinta de cada indicador/parâmetro adotado, a evolução e as tendências da situação por eles sinalizadas ao longo dos dois anos de abrangência (2008 a 2009), as áreas e pontos críticos da Bacia e as orientações para a gestão (COMITÊ DA BACIA HIDROGRÁFICA DO RIO PARDO, 2010).

No ano de 2010, o Comitê instituiu um grupo de trabalho permanente para a elaboração dos Relatórios de Situação, denominado Grupo de Trabalho Permanente do Relatório de Situação dos Recursos Hídricos e Plano de Bacia (GT-RSPB) que, como indicado pela denominação, visa não apenas a identificação das condições ambientais da Bacia, mas também a utilização dos resultados do Relatório como subsídio para o destacamento de estratégias de ação nas revisões do Plano de Bacia. Durante as reuniões, diversas questões pertinentes ao presente trabalho foram observadas. Uma delas se refere à falta de participação pública, sendo o Grupo composto quase que totalmente por integrantes do Comitê.

Além disso, nem todos os setores do colegiado se envolveram nas discussões, o que prejudicou seu processo e resultado, conduzindo a dificuldades de obtenção de informações necessárias para a interpretação dos dados e para a avaliação da relevância dos indicadores específicos e a proposição de outros que fossem considerados importantes pelo Comitê. As dificuldades em se identificar indicadores de impacto condizentes com a realidade da bacia e a não utilização de alguns já existentes, mas que careciam de dados e/ou metodologia consagrada para análise também consistiram em empecilhos para a realização do diagnóstico atual da Bacia em questão.

\section{As contribuições da Avaliação Ambiental Estratégica para o Plano de Bacia do Rio Pardo e demais Planos de Bacias Hidrográficas do país}

As potencialidades de aplicação da AAE para o desenvolvimento de Planos de Bacias Hidrográficas serão apresentadas seguindo o modelo da Diretiva Europeia sobre Avaliação Ambiental Estratégica (2001/42/EC).

\section{Objetivos e escopo}

Quanto a esse item, a AAE apresenta, além dos objetivos presentes na Política, Plano e/ou Programa, os princípios ligados à sustentabilidade presentes nos Tratados Internacionais, Convenções e PPPs ligadas a esse tema. Quando realizada paralelamente à ação em análise, permite que as questões ambientais sejam contempladas em todo o seu desenvolvimento. No caso do Plano de Bacia do rio Pardo, tais pressupostos se fazem presentes por meio da garantia de água em qualidade e quantidade de modo equitativo para as atuais e futuras gerações.

É um processo de avaliação sistemática e pode ser realizada de forma paralela ao Plano por equipe independente, no entanto, a AAE possibilita um maior controle sobre a concretização desses objetivos que servem como ponto de partida para a realização do diagnóstico socioambiental da Bacia, o delineamento de metas e ações a eles condizentes, seu monitoramento e retroalimentação do planejamento. Além disso, ela se constitui em um instrumento importante para garantir que os aspectos ambientais e os impactos advindos do Plano sejam considerados nas etapas iniciais do planejamento, em vez de que estes aspectos se deem apenas durante a análise das atividades pontuais que dele derivam.

Durante a fase de escopo, são definidos os temas ambientais, sociais e econômicos que serão utilizados para orientar os dados a serem coletados e sistematizados na etapa posterior de diagnóstico e para a avaliação dos potenciais impactos e medidas mitigadoras dos cenários alternativos de ações para concretizar o Plano.

A Diretiva Europeia sobre AAE adota os seguintes temas para o escopo: Biodiversidade, Fauna e Flora; Água; Ar, Fatores Climáticos; Solo; População e Saúde Humana; Paisagem e Aspectos Materiais e Patrimônio Cultural e Arquitetônico. Tais Temas são de aplicação obrigatória para a realização de qualquer $\mathrm{AAE}$, mas, dependendo das características intrínsecas de cada PPP, podem não ser incorporados sob justificativas. Do mesmo modo, outros aspectos podem ser incluídos, se pertinentes.

No caso de Planos de Bacia, esses grandes temas podem ser especificados em subtemas, como, por exemplo: 
- Biodiversidade (flora e fauna): existência de espécies endêmicas, espécies-chave representativas dos fragmentos existentes, espécies ameaçadas de extinção, diversidade de espécies nos fragmentos florestais;

- Água: disponibilidade e qualidade hídricas superficiais e subterrâneas, tratamento de esgoto, eventos hidrológicos extremos;

- Recursos Materiais: transporte (impactos sobre a disponibilidade hídrica), agricultura e suas modalidades, indústrias, mineração e demais atividades produtivas que fazem uso ou exercem pressões sobre os recursos hídricos;

- Ar e fatores climáticos: clima, distribuição das precipitações ao longo do ano, umidade;

- Solo: tipos de solo, uso e ocupação, agricultura e suas práticas, erosões e suscetibilidade do solo a processos erosivos, disposição de resíduos sólidos;

- Paisagem: estrutura da paisagem;

- População: demografia e distribuição populacional, projeções de crescimento, saúde (acesso aos serviços de saneamento - coleta do lixo e de esgoto, abastecimento);

- Patrimônio Cultural, Arqueológico e Paleontológico: sítios paleontológicos e arqueológicos.

Durante o escopo também se definem os agentes que participarão da elaboração e monitoramento do Plano. No caso presente, a entidade representativa para tanto é o Comitê de Bacia, composto por setores do Poder Público relacionados à gestão dos recursos hídricos, por usuários da água e pela sociedade civil organizada. As formas e momentos de participação também são definidos, podendo se dar por meio de reuniões ao longo do desenvolvimento da AAE ou em etapas específicas, além de virtualmente, em página eletrônica disponível para tanto, ambas com divulgação prévia.

No escopo também são identificadas as Políticas, Planos e Programas setoriais que interferem e se relacionam aos Planos de Bacia. Uma análise sobre suas diretrizes, objetivos e metas é realizada, de modo a evitar que o conteúdo do Plano de Bacia se distancie de seus pressupostos e se torne impraticável (sobretudo em se tratando de Políticas de âmbito federal e estadual e de diretrizes constitucionais). No caso de Planos e Programas regionais, o Plano de Bacia pode se beneficiar do diagnóstico setorial neles apresentado, facilitando e compatibilizando-se com as coletas e tratamentos de dados. Conflitos entre os princípios que regem a Política de águas no Brasil e os Planos e Programas setoriais e de uso e ocupação do solo se explicitam nesse momento, abrindo um espaço para um diálogo intersetorial para que objetivos comuns, que beneficiem a sociedade como um todo sem prejuízos à capacidade de suporte do meio, sejam estabelecidos.

A existência de Comitês de Bacia Hidrográfica é, nesse sentido, muito vantajosa para a abertura a esse diálogo, pois sua composição abriga os órgãos da administração pública em âmbito estadual e municipal e setores usuários da água, sendo um fórum adequado para a exposição dos diversos interesses e conflitos existentes em torno dos usos múltiplos da água. No entanto, sua existência não é garantia para uma participação efetiva e transparente para a sociedade, conforme aponta Miranda (2003).

Tanto a Política Nacional de Meio Ambiente quanto a Política Nacional de Recursos Hídricos estabelecem a necessidade de articulação intersetorial para o alcance de seus objetivos e, nesse ínterim, a AAE fortalece essas associações, discriminando para cada Política, Plano ou Programa a ser elaborado ou avaliado, as ações estratégicas que contêm diretrizes a serem consideradas. Desse modo, considera-se a ação estratégica em análise, os impactos de seus objetivos sobre o Plano de Bacia do Rio Pardo e se os objetivos de cada ação estão contemplados no Plano, de forma bastante sucinta. Tal metodologia desempenha a tarefa de explicitar os pontos de conflito entre os diversos planejamentos setoriais que incidem sobre o Plano de Bacia, direcionando seus objetivos e metas para que se tornem factíveis e congruentes com objetivos mais amplos. O inverso também é passível de ocorrer, com o Plano de Bacia interferindo sobre outros planos setoriais e territoriais, havendo um maior diálogo entre ambos.

\section{Linha de base ambiental}

A AAE pode auxiliar no diagnóstico das bacias hidrográficas nos seguintes aspectos:

- Por meio da identificação dos dados a serem coletados a partir dos Temas definidos no escopo;

- A partir da análise de outras PPPs, possibilitando a identificação das informações relevantes para o diagnóstico da Bacia e minimizando gastos e tempo em sua obtenção;

- Com a priorização das informações a serem coletadas e trabalhadas;

- Sendo um instrumento que possibilita uma maior participação em todas as etapas do planejamento e conduz à necessidade de independência dos Comitês de Bacia em levantar suas demandas para a produção e coleta de informações.

O diagnóstico depende de informações regionalizadas em âmbito da Bacia hidrográfica e das unidades administrativas, com o nível de detalhamento dependente dos objetivos da gestão, visando à identificação das fragilidades e vocações do meio frente aos aspectos considerados importantes para a gestão. Sendo essa etapa fundamental para a derivação das metas do Plano de Bacia, é importante que os principais problemas sejam identificados espacialmente e, para isso, os dados primários ou brutos precisam ser manipulados para mostrar as áreas problemáticas e suas tendências.

Levantamento de alternativas para as metas de ação

A Lei No. 9433/97 determina que o conteúdo dos Planos de Bacia Hidrográfica contemple análises alternativas de crescimento demográfico, as tendências das atividades produtivas e as modificações 
dos padrões de uso e ocupação do solo. Segundo Silva e Pruski (2000), para que tal análise se efetue, os núcleos populacionais rurais e urbanos devem ser levantados, assim como as correntes migratórias, as legislações de uso e ocupação do solo, os projetos de loteamento e os distritos industriais protocolados nas prefeituras municipais e seus zoneamentos ambientais

No Plano de Bacia do Rio Pardo, os cenários elaborados foram relativos às metas identificadas para a efetivação dos seus objetivos, tendo por base o contingenciamento de verbas para tanto. Desse modo, elaborou-se o cenário desejável, piso e recomendado, apresentando as ações e sua potencialidade de realização em curto, médio e longo prazo de acordo com os financiamentos garantidos e passíveis de obtenção. No entanto, não se efetuaram projeções alternativas de crescimento e de distribuição demográfica, de atividades produtivas e ocupação do solo considerando as tendências observadas, as legislações vigentes e o contexto social, político e econômico de inserção da Bacia, prejudicando, desse modo, as etapas posteriores de planejamento.

Tendo por base os temas identificados no escopo da AAE e a partir do diagnóstico existente, seria possível realizar projeções no horizonte de atuação do Plano para cada tópico considerado, criando-se cenários tendenciais sobre a situação futura dos recursos hídricos da Bacia, visando uma avaliação integrada e contextualizada dos temas em análise e a identificação das denominadas "janelas de decisão" (Partidário, 2002), ou seja, dos momentos e pontos de intervenção para modificar as situações problemáticas atuais e futuras.

A título de exemplificação, a partir do diagnóstico atual da biodiversidade na Bacia, identificada como crítica no Plano, mesmo na ausência de informações precisas, cujos impactos advêm da expansão agrícola e urbana que conduzem à fragmentação de habitats, criam-se cenários de situação futura dos agentes impactantes para a elaboração de metas que incidam sobre os mesmos. Os Planos de desenvolvimento agrícola e Diretores Municipais, os Planos Plurianuais e demais investimentos no setor agrícola e imobiliário da região podem servir de início para as projeções. Desse modo, elabora-se um cenário com as tendências dos setores, os quais atualmente apresentam um planejamento desarticulado entre si, dada a predominância dos fatores econômicos na gestão setorial vigente no país.

A partir da delimitação das áreas problemáticas, as metas de ação podem ser traçadas com uma maior segurança, pois os fatores intervenientes terão sido considerados. Nesse momento, ações alternativas são levantadas para a implementação dos objetivos do Plano, que passarão por uma análise de impactos ambientais, sociais e econômicos para a seleção daquelas mais adequadas do ponto de vista da sustentabilidade ambiental.

\section{Avaliação dos impactos ambientais, econômicos e sociais das alternativas de ação}

A AAE traz uma contribuição importante ao Plano de Bacia nesse momento, pois oferece metodologias de avaliação de impactos cumulativos, diretos e indiretos de curto e longo prazo para as diferentes ações propostas.

$\mathrm{Na}$ ausência da AAE, as alternativas levantadas correm o risco de se tornar soluções imediatistas, sem uma visão de futuro, de modo reativo ao invés de proativo. Ao contrário das alternativas levantadas nos projetos pontuais com os Estudos de Impacto Ambiental, as alternativas da AAE apresentam um conteúdo estratégico próprio ao planejamento de longo prazo. Desse modo, a AAE auxilia os tomadores de decisão a levantarem alternativas mais sustentáveis do ponto de vista ambiental, social e econômico por meio da avaliação de seus potenciais impactos.

Visando a abordagem da sustentabilidade ambiental estratégica, Therivel (2004) apresenta uma hierarquia para a proposição e análise de alternativas, seguindo o padrão desenvolvido para a gestão de resíduos sólidos de reduzir, reutilizar, reciclar e dispor, de modo a minimizar a utilização dos recursos naturais antes de propor novos projetos de desenvolvimento, em um modelo de gestão preventivo em vez de reativo. Uma vez que medidas de redução da demanda tenham sido efetuadas, buscam-se as diversas formas viáveis para atendê-la. Por exemplo, para atender às demandas por abastecimento de água, pode-se optar por águas subterrâneas, armazenamento de água de chuvas, águas superficiais de rios e lagos e mesmo a dessalinização de águas costeiras (THERIVEL, 2004).

Para Therivel (2004), no entanto, há limitações para a proposição de alternativas, que dizem respeito à sua factibilidade e legabilidade frente ao contexto em que o problema se insere. No exemplo dado acima sobre a demanda por abastecimento, a dessalinização não se mostra uma alternativa viável para a realidade das bacias interiores brasileiras, o que a torna infactível.

O procedimento corrente, após a desqualificação de ações inviáveis é avaliar cada alternativa proposta frente às metas do Plano, em termos de como levam ao seu alcance. A avaliação é inicialmente qualitativa, havendo uma identificação dos potenciais impactos de cada alternativa em relação aos objetivos do Plano. Para tanto, pode-se utilizar uma matriz de impactos, tendo como critérios para a avaliação os fatores ambientais, sociais e econômicos relevantes para a ação estratégica, de acordo com os Temas definidos no escopo da AAE. Para cada impacto negativo apresentado, são avaliadas possibilidades de mitigação que possam tornar a ação viável. Desse modo, medidas compensatórias, estudos locacionais para a implantação de empreendimentos e alternativas tecnológicas são propostos pela equipe que realiza a AAE.

Após realizada a etapa de avaliação dos impactos e de suas mitigações, cabe aos órgãos gestores dos recursos hídricos (com presença fundamental do Comitê de Bacia), organizações não governamentais e municipalidades que regem o uso e ocupação do solo nas cidades e meio urbano discutirem, junto à equipe responsável pela AAE, acerca dos benefícios e prejuízos decorrentes da escolha de cada uma das alternativas apresentadas.

As contribuições apresentadas pela implementação da AAE nessa etapa do Plano consistem no levantamento de alternativas plausíveis 
para a solução ou minimização de um problema considerado relevante pelo Comitê de Bacia, com a identificação e análise dos impactos de cunho ambiental, social e econômico dessas frente aos fatores ou temas identificados no escopo do estudo. Desse modo, a AAE, quando realizada paralelamente aos Planos de Bacia e por equipe politicamente isenta e qualificada em termos científicos, diminui as possibilidades de que decisões sejam tomadas sem uma análise mais aprofundada do problema e de suas possíveis soluções, incorporando a visão da sustentabilidade ambiental.

\section{Monitoramento}

O monitoramento da AAE é realizado acompanhando-se os indicadores de desempenho das metas previstas. Dessa forma, para cada decisão tomada, desenvolve-se um índice ou indicador de performance viável de ser analisado, ou seja, que se baseie em dados coletáveis e metodologia aplicável, a fim de detectar a situação da gestão dos recursos hídricos.
No caso dos Planos de Bacia do estado de São Paulo, está sendo feito o uso de indicadores de situação da Bacia desde o ano de 2009, baseados no modelo FPEIR da EEA, como anteriormente discutido. Entretanto, tais indicadores fornecem um diagnóstico da situação atual da Bacia e suas tendências, sem, no entanto, estar diretamente ligados ao grau de alcance das metas e ações do Plano. Para que este se efetive, o monitoramento deveria ser realizado nesses moldes para mostrar se e como as ações estão sendo efetuadas e, caso afirmativo, se estão sendo traduzidas em melhorias para os problemas enfrentados na Bacia.

A utilização da AAE, que faz uso de indicadores de desempenho para avaliar o Plano em elaboração e o próprio Relatório final da AAE, possibilita que o planejamento se dê de forma adaptativa, de modo a se adequar às mudanças que forem surgindo.

A Figura 2 ilustra as contribuições da AAE para a formulação e acompanhamento de Planos de Bacia, tendo em vista as etapas discutidas.

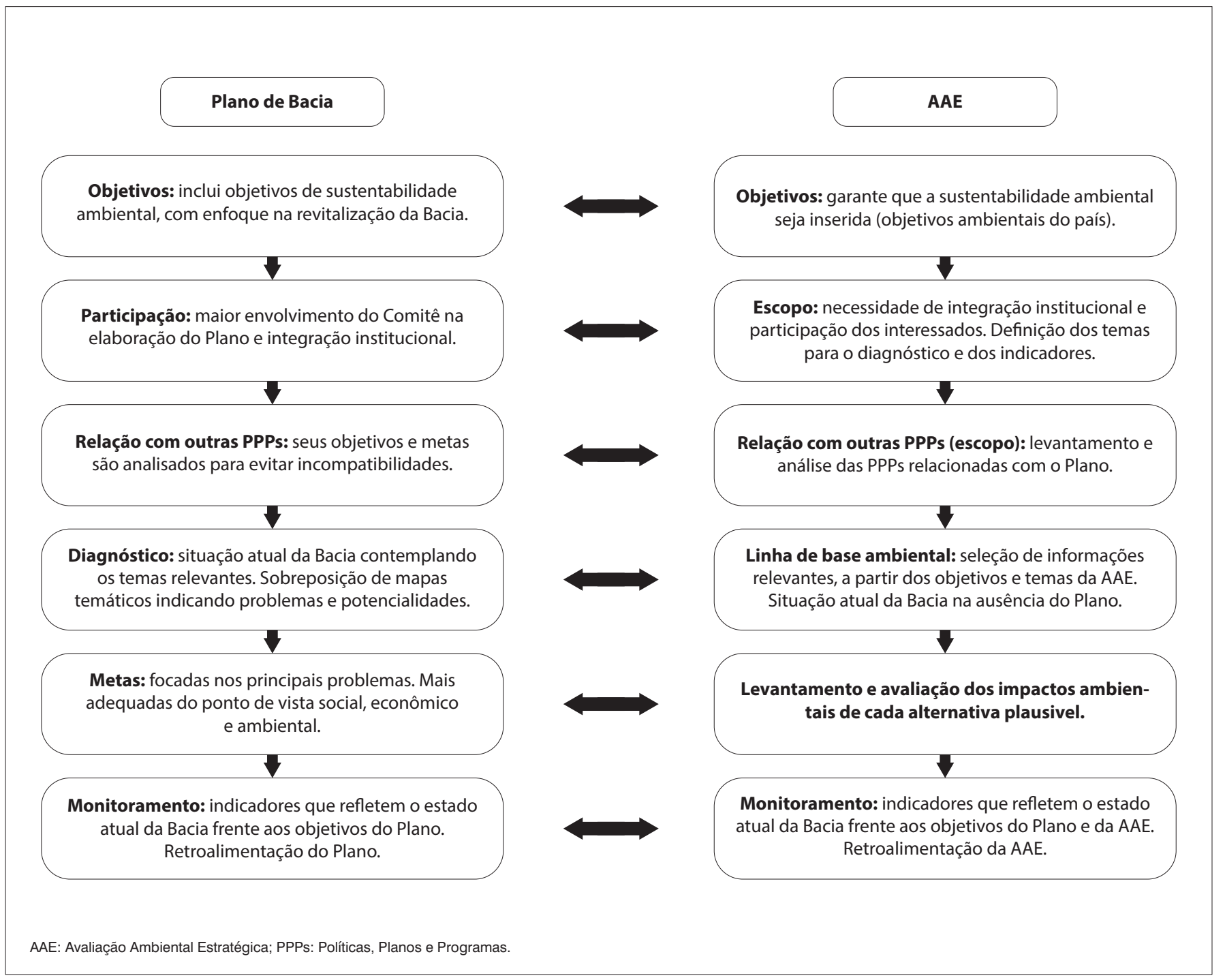

Figura 2 - Influências da Avaliação Ambiental Estratégica sobre o Plano de Bacia, quando realizados de forma paralela. 
A partir da análise da Figura 2, pode-se observar que a realização de uma AAE paralela aos Planos de Bacias Hidrográficas traria diversas contribuições, tais como: a incorporação de objetivos de sustentabilidade ambiental e socioeconômica aos Planos, de modo a minimizar a visão setorizada da gestão de recursos hídricos no país; assegurar uma participação mais ampla no planejamento, com maior independência dos Comitês no levantamento de suas demandas; a articulação entre as diversas ações estratégicas que incidem sobre os recursos hídricos em âmbito da Bacia; a identificação dos principais temas a serem trabalhados ao longo do diagnóstico, prognóstico e monitoramento do Plano; a avaliação dos impactos ambientais e socioeconômicos positivos e negativos, diretos, indiretos e cumulativos das metas e ações do Plano e a identificação de indicadores de monitoramento deste que auxiliem no acompanhamento das ações propostas e nas possíveis readequações a serem realizadas na revisão do Plano de Bacia.

\section{Conclusões}

A partir das análises efetuadas nesta pesquisa, algumas críticas podem ser levantadas quanto ao planejamento de Bacias Hidrográficas no estado de São Paulo, com enfoque para a Bacia do Rio Pardo, tais como: falta de independência dos Comitês na elaboração dos Planos, que são realizados por consultoras que efetuam poucas consultas com o colegiado quanto às suas demandas por informações; falta de dados em quantidade adequada e escala apropriada para o diagnóstico e monitoramento da Bacia; ausência de articulação entre os diversos setores que fazem uso e/ou cujas atividades impactam os recursos hídricos; falta de diálogo entre as prefeituras municipais e o Comitê de Bacia; ausência de articulação entre as ações estratégicas que se relacionam com os recursos hídricos; pouca participação da sociedade no Comitê de Bacia e de divulgação do Plano de Bacia e suas metas; visão setorizada dos recursos hídricos em detrimento de uma abordagem que o insira como um componente dos ecossistemas, o que conduz a uma dissociação entre os Planos de Recursos Hídricos e os diversos planos e programas ambientais; metas e ações dos Planos de Bacia de caráter generalistas, que não são derivadas em Programas de ação e indicadores de situação dos recursos hídricos dissociados das metas do Plano de Bacia.

A partir da análise das metodologias empregadas em Avaliações Ambientais Estratégicas, nos moldes da Diretiva Europeia sobre AAE (2001/42/EC), foi possível identificar algumas contribuições que o instrumento traria para a elaboração e acompanhamento de Planos de Bacias Hidrográficas, tais como: garantir a incorporação dos princípios de sustentabilidade ambiental, social e econômica no desenvolvimento de PPPs, em acordo com os tratados internacionais firmados com o Brasil e demais políticas ambientais existentes; identificação de temas para o levantamento de informações sobre a Bacia; sistematização da informações para a realização do diagnóstico ou linha de base, que apresenta a situação atual da Bacia; levantamento de alternativas plausíveis para solucionar e minimizar os problemas identificados na Bacia em horizontes de curto, médio e longo prazos; avaliação dos impactos ambientais e socioeconômicos de cada alternativa segundo suas tipologias, ou seja, como positivos e negativos, diretos, indiretos e cumulativos; escolha das alternativas mais adequadas em termos ambientais e socioeconômicos a partir dos impactos analisados e as medidas mitigadoras necessárias; identificação de indicadores para o monitoramento do Plano de forma contínua, para avaliar a implementação das medidas, os problemas encontrados e, desse modo, retroalimentar o planejamento.

Apesar da importância constatada da aplicação da AAE, há diversos empecilhos em sua utilização. Inicialmente, não há regulamentação desse instrumento no país, mas apenas ações isoladas de aplicação com objetivos e metodologias distintas entre si. Portanto, sua regulamentação é imprescindível para definir em quais situações a AAE seria aplicada e de que forma, se paralela ao Plano a ser avaliado ou em separado, como tem sido feito com os Estudos de Impacto Ambiental.

Além disso, é necessário constar as diretrizes que devem reger sua elaboração, as metodologias empregadas e os resultados esperados. Para que a AAE de fato influencie o planejamento, recomenda-se que a mesma seja realizada de forma paralela às PPPs em estudo e que garantias sejam feitas para a articulação efetiva entre o planejamento setorial, como forma de implementar os pressupostos do desenvolvimento sustentável no país.

A falta de informações importantes, principalmente de cunho ambiental consiste em outro entrave para a AAE, que deve ser sanado pelo Poder Público. Bancos de dados ambientais necessitam ser disponibilizados para dinamizar sua elaboração e garantir que essa dimensão seja incorporada par a par com as questões econômicas que prevalecem no planejamento setorial e territorial do país.

Por fim, para que a AAE se dê de modo transparente e incorporando os anseios dos atores afetados e interessados nos planejamentos, uma divulgação ampla antes de sua realização deve ser feita para a abertura ao diálogo e à participação, a fim de que a equipe responsável por seu desenvolvimento considere todos os interesses envolvidos. Caso contrário, o instrumento pode ser utilizado como um ato burocrático que não exerce influência na elaboração de PPPs. 


\section{Referências}

BRASIL. (1997) Lei No. 9.433, de 8 de janeiro de 1997. Política Nacional dos Recursos Hídricos. Diário Oficial da União. Brasília, DF: Imprensa Oficial.

COMITÊ DA BACIA HIDROGRÁFICA DO RIO PARDO. (2010) Relatório de situação dos recursos hídricos 2010 (ano base 2009). Ribeirão Preto: CBH-Pardo, 88 p.

CPTI - Cooperativa de Serviços e Pesquisas Tecnológicas e Industriais. (2008) Plano de Bacia da Unidade de Gerenciamento de Recursos Hídricos do Pardo (UGRHI 04) - Revisão para atendimento da Deliberação CRH 62. Relatório Técnico 401/08. São Paulo: CPTI, 370 p.

EMPINOTTI, V. (2010) Relatório Final. Avaliação dos 20 anos do Sistema Integrado de Gerenciamento de Recursos Hídricos - SIGRH. São Paulo: Empinotti Ambiental, 125 p.

GOVERNO DO ESTADO DE SÃO PAULO. Secretaria do Meio Ambiente. (2010) Situação dos recursos hídricos no estado de São Paulo: ano base 2008. São Paulo: Coordenadoria de Recursos Hídricos, 222 p.
GULLÓN, N. (2005) Links between the water framework directive and SEA. In: SHMIDT, M. \& JOÃO, E. (Eds.) Implementing strategic environmental assessment. Berlim: Springer-Verlag, p. 513-521.

MIRANDA, C.O. (2003) O Papel político-institucional dos comitês de bacia hidrográfica no estado de São Paulo: um estudo de caso. In: FELICIDADE, N.; MARTINS, R.C.; LEME, A.A. (Eds.) Uso e gestão dos recursos hídricos no Brasil: velhos e novos desafios para a cidadania. São Carlos: RiMa, p. 135-148.

PARTIDÁRIO, M.R. (2002) Avaliação ambiental estratégica. Brasília: MMA/SQA, $92 \mathrm{p}$.

PORTO, M. \& TUCCI, C.E.M. (2009) Planos de recursos hídricos e as avaliações ambientais. REGA, v. 6, n. 2, p. 19-32.

SILVA, D.D. \& PRUSKI, F.F. (2000) Gestão de recursos hídricos: aspectos legais, econômicos, administrativos e sociais. Brasília: Secretaria de Recursos Hídricos; Porto Alegre: Universidade Federal de Viçosa e Associação Brasileira de Recursos Hídricos, 659 p.

THERIVEL, R. (2004) Strategic environmental assessment in action. Reino Unido: Earthscan, 276 p. 